\title{
Erratum to: A comparative analysis of photosynthetic recovery from thermal stress: a desert plant case study
}

\author{
Ellen M. Curtis • Charles A. Knight • Katherina Petrou • \\ Andrea Leigh
}

Published online: 15 October 2014

(C) Springer-Verlag Berlin Heidelberg 2014

\section{Erratum to: Oecologia (2014) 175:1051-1061 DOI 10.1007/s00442-014-2988-5}

We notify of an error in the caption of Fig. 1, relating to $\Delta F / F_{\mathrm{M}^{\prime}}$ and the associated equation. The caption should read as follows:

Fig. 1 Photochemical quantum yield in response to heat stress treatments, as demonstrated in Acacia papyrocarpa during summer. a Control measurements of maximum quantum yield of PSII $\left(P S_{F V / F_{\mathrm{M}}}\right)$ and effective quantum yield $\left(P S_{\Delta F / F_{\mathrm{M}^{\prime}}}\right)$ were measured prior to heat stress. $F_{\mathrm{V}} / F_{\mathrm{M}}$ was measured $2 \mathrm{~h}$ after stress treatment and after a further recovery period of ca. $16 \mathrm{~h}\left(D 2_{F V / F_{\mathrm{M}}}\right.$, indicating day 2 of measurements) at $46,48,50,52-54{ }^{\circ} \mathrm{C}$ and a control temperature of $28{ }^{\circ} \mathrm{C} . \mathbf{b} \Delta F / F_{\mathrm{M}^{\prime}}$ was measured immediately following stress treatment, $1.5 \mathrm{~h}$ after and on day 2 following dark-adapted measurements and an additional $15 \mathrm{~min}$ under control conditions in order to light-adapt samples. c The difference between pre-stress and day 2 maximum quantum yield was used as a simple measure of damage to PSII $\left(D_{\mathrm{PSII}}=\left(D 2_{F V / F_{\mathrm{M}}} /\right.\right.$ $\left.\mathrm{PS}_{F V / F_{\mathrm{M}}}\right)$ ), solid symbols. Recovery from heat stress was measured as the proportion of initial loss of photosynthetic efficiency that was recovered by day 2 of measurements $\left(R_{\Phi \mathrm{PSII}}=\left(D 2_{\Delta F / F_{\mathrm{M}^{\prime}}}-1.5 \mathrm{~h}\right) /\left(\mathrm{PS}_{\Delta F / F_{\mathrm{M}^{\prime}}}-1.5 \mathrm{~h}\right)\right)$, open symbols. For all data points $n=10 \pm$ standard error. Dashed lines are for ease of reading patterns and not representative of continuous time

The online version of the original article can be found under doi:10.1007/s00442-014-2988-5.

E. M. Curtis $(\bowtie) \cdot$ A. Leigh

School of the Environment, University of Technology, Sydney,

15 Broadway, PO Box 123, Ultimo, NSW 2007, Australia

e-mail: ellen.curtis@uts.edu.au

C. A. Knight

Biological Sciences Department, California Polytechnic State

University, San Luis Obispo, CA 93407, USA

K. Petrou

Plant Functional Biology and Climate Change Cluster (C3),

School of the Environment, University of Technology, Sydney,

15 Broadway, PO Box 123, Ultimo, NSW 2007, Australia 